\title{
Threshing Damage to Radicle Apex Affects Geotropic Response of Winterfat
}

\author{
D. TERRANCE BOOTH
}

\begin{abstract}
The acute end of a winterfat [Eurotia lanata (Pursh) Moq.; Ceratoides 1. (Pursh) J.T. Howell] seed is formed by the apex of the radicle and of the cotyledons. It is postulated that this shape makes the embryo root cap especially susceptible to damage during threshing and that such damage is the cause of a high percentage of threshed germinated seed (germinant) lacking positive geotropism. This study consisted of examining germination behavior and post germination anatomy of the root apex of germinants with and without positive geotropism. The radicle apex was found to be damaged in $25 \%$ of the threshed seed. Eighty-five percent of the germinants from undamaged seed had positive geotropism as compared to $53 \%$ from the damaged seed. The latter had a range of anatomical aberrations in which the root cap was missing or seriously abnormal. It is concluded that the standard method of hammer mill threshing of winterfat fruits results in $25 \%$ of the seed sustaining damage to the radicle apex. This damage causes a loss of root cap functions, particularly the sensing of gravity. It is recommended that plantings be made by broadcasting whole fruits, rather than by drilling threshed seed.
\end{abstract}

Because of the advantages threshed seed have in mechanical planting and storage, winterfat [Eurotia lanata (Pursh) Moq.; Ceratoides l. (Pursh) J.T. Howell] fruits (utricle + bracts) are

\footnotetext{
The author is range scientist, USDA-Agricultural Research Service, High Plains Grasslands Research Station, 8408 Hildreth Road, Cheyenne, Wyo. 82009.

Appreciation is extended to Dr. J.A. Fernandez for the microscope slide preparation and assistance in photography, and Larry W. Griffith for his technical assistance in the germination studies. Threshed seed (NM-333) was provided by USDA-SCS, Los Lunas Plant Materials Center and whole fruits were furnished by Utah Division of Wildlife Resources (W-82-R).

Manuscript received April 21, 1983.
}

sometimes threshed by hammer milling at $550 \mathrm{rpm}$ with $6.4-\mathrm{mm}$ screen (Wendall Oaks, USDA-Soil Conservation Service, Los Lunas Plant Materials Center, personal communication 1979) or at 1,000-1,200 rpm using a 7.9-mm screen (Stevens et al. 1977). However, Booth and Schuman (1983) found that up to $24 \%$ of germinated seed (germinants) from threshed seed did not show positive geotropism. This aberration also has been observed by workers at the Los Lunas Plant Materials Center (Joseph Fraser, personal communication 1982).

The structure of the winterfat seed makes the radicle apex in the winterfat seed especially vulnerable to damage during threshing because the embryo encircles the perisperm with the radicle and cotyledon tips forming an acute end (Fig. 1A). This study was conducted to learn if damage to the radicle apex was responsible for the lack of positive geotropism. The root cap is known to be the organ which perceives gravitational stimuli (Juniper et al. 1966). Konings (1968) reported that loss of the distal 0.2 to $0.4 \mathrm{~mm}$ of root cap of 2-day-old pea (Pisum sativum) seedlings reduced tropic response progressively. Removal of the entire root cap $(0.5 \mathrm{~mm})$ caused complete loss of tropic response.

The winterfat root has an open type apex. In this type of root cap, the cells at the distal face of the quiescent center, when they divide, contribute cells to the root cap. By the time the radicle of the developing embryo becomes dormant, prior to fruit dispersal, root cap cell differentiation, including development of the quiescent center, has occurred (Byrne 1971). The very small size of the root cap in the imbibed winterfat embryo, even smaller in the dry seed, emphasizes that minute damage can result in removal of the root cap and the contributing meristem. 


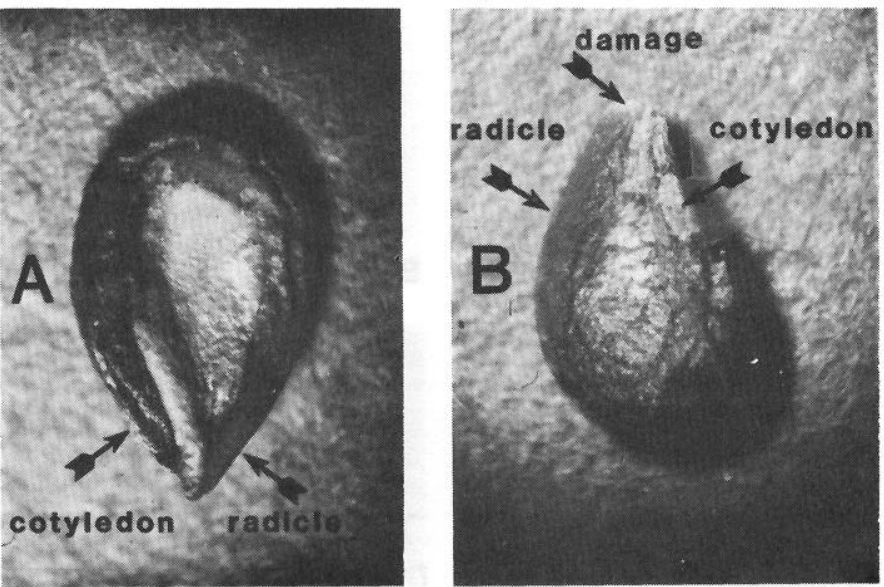

Fig. 1-A. Undamaged threshed winterfat $(\times 20)$

Fig. 1-B. Damaged threshed winterfat $\times 20)$

\section{Materials and Methods}

Threshed seeds of winterfat, NM-333, (1979 harvest threshed at $550 \mathrm{rpm}$ with $6.4-\mathrm{mm}$ screen and stored under refrigeration) were used for this study. Four groups of 100 randomly selected seeds were examined microscopically for damage to the radicle apex. This method also was used to select 500 damaged seeds and 500 undamaged seeds. Usually injury to the radicle apex was not visible to the unaided eye.

The 2 groups of 500 seeds were divided into 5 replications of 100 seeds each. The groups were soaked for 48 hours in water at $0^{\circ} \mathrm{C}$ (Booth and Schuman 1983) and placed on inclined acrylic plastic (Plexiglas) plates (Jones and Cobb 1963) with the apex horizontal and the radicle dorsal. The seeds were incubated at $21^{\circ} \mathrm{C}$ for 16 hours followed by $4.4^{\circ} \mathrm{C}$ for 8 hours. Germination and geotropism were scored the third day of incubation. Two $\times$ two chi-square tables were constructed for seed classes to compare germination and growth of damaged and undamaged seeds. The lengths of the radicles/primary roots were measured and a least-squares analysis of variance comparing mean length was performed. Germinants with radicles less than $5 \mathrm{~mm}$ were put in a 'no growth' category with nongerminating seeds. This assured adequate growth for a geotropic response.

Germinants from the above study, with and without a tropic response, were randomly selected for histological study of root apices. Histological examination also was done (using a Utah collection) for imbibed ungerminated embryos and for whole fruit germinants. Samples were killed and fixed in FAA (Sass 1958), dehydrated and cleared in an alcohol-toluene series, and embedded in paraffin. Mounted, longitudinal sections $(8 \mu$ thick) were dewaxed in xylene and brought down to $50 \%$ alcohol to remove a tracer stain used during embedding. Sections then were brought up to absolute alcohol and stained for 1 minute with $0.5 \%$ fast green in $1: 1$ clove oil:absolute alcohol, destained in $1: 1$ clove oil:absolute alcohol, passed through 3 changes of xylene, and mounted in synthetic resin.

\section{Results}

The radicle apex was found to be damaged in 25\% (95\% confidence limits $\pm 3 \%$ ) of the threshed seed (Fig. 1B).

From the seeds found to be undamaged, $85 \%$ showed a positive geotropic response, as compared to $53 \%$ from the damaged group. This difference was highly $(P<<.005)$ significant (Table 1). It also indicates that $15 \%$ of this seed lot has a 'natural' geotropic deficiency. The 'no growth' category (Table 2) contained $41 \%$ and $33 \%$ of damaged and undamaged seeds, respectively, and indicates a significant $(P<.025)$ advantage for undamaged seed. Germinants
Table 1. Two $\times$ Two Chi-square comparison of threshed winterfat seed classes.

\begin{tabular}{lccl}
\hline \hline & \multicolumn{2}{c}{ Undamaged seed Damaged seed } & Total \\
\hline Positive & 285 & 158 & 443 \\
geotropism & $(235.14)$ & $(207.85)$ & \\
No & 51 & 139 & 190 \\
geotropism & $(100.85)$ & $(89.14)$ & \\
Total & 336 & 297 & 633 \\
$\chi^{2}=75.05$ & & & \\
DF $=1$ & & & \\
$P<<.005$ & & & \\
\end{tabular}

without a tropic response to gravity had slower radicle growth (Table 3 ), though the differences at 3 days incubation were significant only at the $10 \%$ level.

Table 2. Two $\times$ Two Chi-square comparison of germination and growth between damaged and undamaged winterfat seed.

\begin{tabular}{|c|c|c|c|}
\hline \multirow[b]{2}{*}{ Growth } & \multicolumn{2}{|c|}{ Undamaged seed Damaged seed } & \multirow{2}{*}{$\begin{array}{r}\text { Total } \\
633\end{array}$} \\
\hline & $\begin{array}{c}336 \\
(316.5)\end{array}$ & $\begin{array}{c}297 \\
(316.5)\end{array}$ & \\
\hline No growth ${ }^{1}$ & $\begin{array}{l}164 \\
(183.5) \\
\end{array}$ & $\begin{array}{l}203 \\
(183.5) \\
\end{array}$ & 367 \\
\hline Total & 500 & 500 & 1,000 \\
\hline $\begin{array}{l}\chi^{2}=6.5 \\
D F=1 \\
P<.025\end{array}$ & & & \\
\hline
\end{tabular}

'Nongerminating seed plus germinants with radicles $<5 \mathrm{~mm}$.

Table 3. Root lengths of winterfat germinants at $\mathbf{3}$ days incubation.

\begin{tabular}{lc}
\hline \hline Variable & Mean radicle length mm' \\
\hline Main effects & \\
undamaged seed & $12.0 \mathrm{a}$ \\
damaged seed & $11.1 \mathrm{a}$ \\
positive geotropism & $12.2 \mathrm{a}$ \\
no geotropism & $10.9 \mathrm{~b}$ \\
Interactions & \\
undamaged seed, positive geotropism & $13.2 \mathrm{a}$ \\
undamaged seed, no geotropism & $10.9 \mathrm{a}$ \\
damaged seed, positive geotropism & $11.2 \mathrm{a}$ \\
damaged seed, no geotropism & $11.0 \mathrm{a}$
\end{tabular}

${ }^{1}$ Means followed by the same letter are not significantly different at the .10 level of probability as tested by a least-squares analysis of variance.

Histological examination of the root apices of threshed seed germinants from both categories of geotropic response revealed a range of anatomical aberrations in germinants with no geotropism (compare Fig. 2 and Fig. 3). Twelve slides were obtained of germinants in the damaged, no geotropism categories, and all showed the root cap missing or seriously damaged. Twenty-five slides were obtained from the no damage, positive geotropism group; the root apex in all of these germinants appeared normal.

Growth in damaged plants, where meristematic cells were missing, consisted almost totally of cell elongation (Fig. 3-B). Where some meristematic cells remained, cell division appeared random (Fig. 3-A), or with some differentiation (Fig. 3C \& D). In all cases 


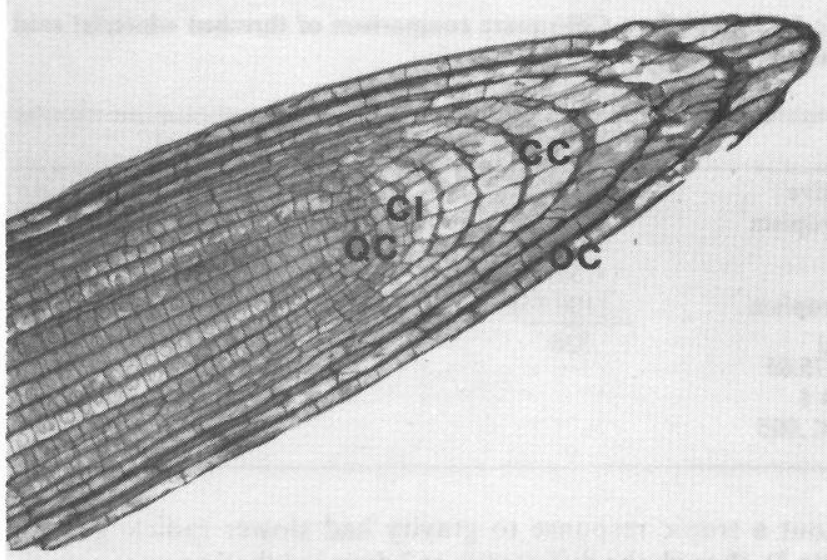

Fig. 2. Healthy root apex of winterfat germinant $(\times 200)$ showing central cap (CC), out (CC), outer cap (OC), cap initials (CI) and quiescent center $(Q C)$.

impaired growth resulted in abnormal morphology such that a functional root cap had not developed.

Histological evidence for the 'natural' lack of geotropic response seen in $15 \%$ of the undamaged seed (Table 1) was not found. Root caps from whole fruit germinants which lacked positive geotropism appeared normal, indicating that this lack of positive geotropism is due to factors other than malformation of the embryo root cap. The root cap of imbibed, nongerminated winterfat embryos was found to be about $0.2 \mathrm{~mm}$ long.

\section{Discussion}

Germinants without a positive geotropic response (beyond the observed $15 \%$ 'naturally' inadequate seeds) are those seeds which sustained damage to the apical meristem (cap initials and the quiescent zone-Fig. 2) of the radicle and therefore were unable to respond to gravitational stimulus. This conclusion is supported by the increase in deficient germinants in the case of damaged seed, (Table 1), by the histological evidence presented, and by the previous work by Juniper (1966) and Konings (1968).

If it is assumed that growth by a radicle without a root cap is random, the 158 observations recorded for damaged seed, positive geotropism (Table 1) may be high. A completely random phenomenon will produce more or less equal numbers in each category, and the close agreement in both number of observations of the 2 groups in the damaged class (158 vs 139), and the fact that both groups have the same growth rate of the radicle (Table 3), leads one to suspect the damaged, positive geotropism group included germinants that in fact had no tropic response to gravity.

The $15 \%$ of the undamaged seeds found lacking positive geotropism is the same value reported earlier for germinants from whole fruits of the same lot (Booth and Schuman 1983).

The 3 functions of the root cap, other than the perception of gravitation stimuli, are (a) to protect the root meristem (b) to open a passage for the root through the soil (Haberland 1914), and (c) the secretion of mucilage by the golgi apparatus in the outer cells of the cap (Juniper and Pask 1973). Mucilage is believed to function as a lubricant and to facilitate mycorrhizal associations (Barlow 1975). The damage evidenced by the slides make it very doubtful that the root apex could fulfill any of the functions attributed to the root cap.

The above functions are important to the establishment of the seedling, both in functional capacity and in relation to the time required for adequate soil penetration. Winterfat is a species adapted to germination near the soil surface where the time is short when soil moisture conditions are right for establishment. Even minimal damage may be lethal as evidenced, in part, by the characteristic low establishment from threshed seed (Booth and Schuman
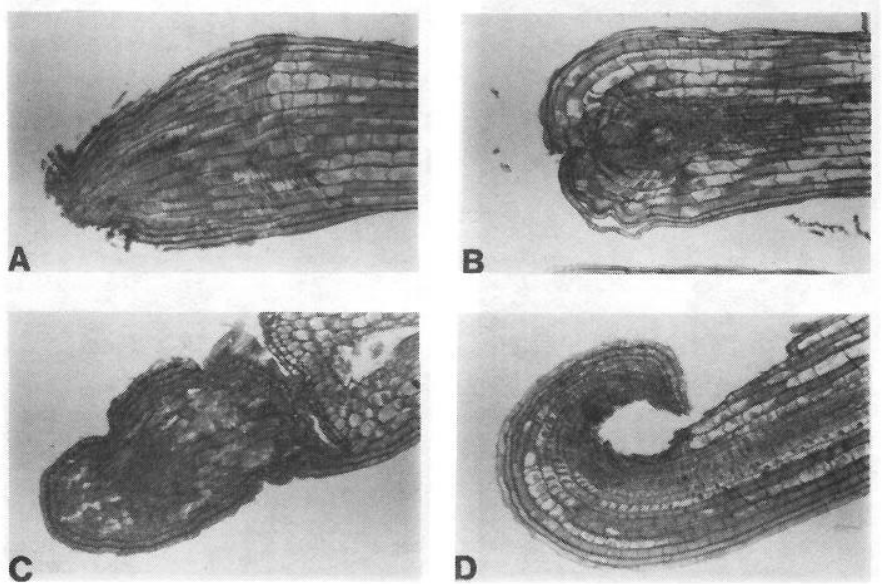

Fig. 3 A-D. Damaged root apices of winterfat germinations $(\times 100)$.

1983) and high mortality of threshed seedlings which do 'establish' from seed (Strickler 1956).

Hypotheses are currently being advanced which ascribe geotropic curvature to a growth inhibitor produced by the root cap which reduces the rate of cell expansion in the lower side of the root (Firn and Digby 1980, Audus 1975). This could explain the observed greater cell elongation in damaged radicles (compare Fig. 2 and Fig. 3) and would be an indication that the greater radicle length associated with positive geotropism (Table 3 ) is due to meristematic cell division, since tropic response would induce some inhibition of cell elongation.

\section{Conclusions and Recommendations}

Winterfat seed threshed by the SCS (Wendall Oaks, personal communication 1979) method of hammer milling results in $25 \%$ of the seed sustaining microscopic damage to the radicle apex, causing malformation or loss of the root cap. This results in loss of root cap functions, particularly the sensing of gravity.

It is recommended that winterfat fruits not be threshed. Plantings can be made by broadcasting the whole fruits on rough seedbeds. Better methods are being developed. Work by the author in adapting the fluid drilling methods of Currah et al. (1974) show that this technique is potentially a superior method for dispersing winterfat and other fluffy propagules.

\section{Literature Cited}

Audus, L.J. 1975. Geotropism in roots. p. 327-363. In: Torrey, J.G. and Clarkson, D.C. (eds.), The Development and Function of Roots. Academic Press. London \& New York.

Barlow, P.W. 1975. The Root Cap. p. 21-54. In: Torrey, J.G. \& Clarkson, D.T. (eds.), The Development and Function of Roots. Academic Press. London.

Booth, D.T., and G.E. Schuman. 1983. Seedbed ecology of winterfat: fruit versus threshed seeds. J. Range Manage. 36:387-390.

Byrne, J. 1971. p. 3-27. In: E. W. Carson (ed.), The Plant Root and Its Environment. Univ. Press of Virginia. Charlottesville.

Currah, I.E., D. Gray, and T.H. Thomas. 1974. The sowing of germinating vegetable seeds using a fluid drill. Annals of Applied Biology 76:311-318.

Firn, R.D., and J. Digby. 1980. The establishment of tropic curvatures in plants. Annu. Rev. Plant Physiol. 31:131-148.

Haeberlandt, G. 1914. Physiological Plant Anatomy (translation of 4th German edition by M. Drummond). MacMillan, London.

Jones, L.G., and R.D. Cobb. 1963. A technique for increasing the speed of laboratory germination testing. In: Proc. Ass. Offic. Seed Analysts. 53:144-160.

Juniper, B.E., S. Gooves, B. Landau-Schacher, and L.J. Audus. 1966. Root cap and the perception of gravity. Nature 209:93-94.

Juniper, B.E., and G. Pask. 1973. Directional secretion by the Golgi bodies in maize root cells. Planta 109:225-231. 
Konings, H. 1968. The significance of the root cap for geotropism. Acta Bot. Neerl. 13:566-622.

Sass, John E. 1958. Botanical microtechnique. Iowa State College Press. Ames, lowa.
Stevens, R., B.C. Giunta, K.R. Jorgensen, A.P. Plummer. 1977. Winterfat (Ceratoides lanata). Utah State Div. of Wildlife Res. Pub. No. 77-2.

Strickler, G.S.S. 1956. Factors affecting the growth of whitesage [Eurotia lanata (Pursh.) Moq.]. M.S. Thesis, Univ. of Nevada, Reno. 